\title{
Modulatory effect of fermented Tetracarpidium conophorum (African walnut) supplemented diet on cadmium-induced toxicity in rats
}

\author{
1,3,*Alejolowo O.O., ${ }^{1}$ Anointing P.E., ${ }^{1,3}$ Nwonuma C.O., ${ }^{1,3}$ Awakan O.J., ${ }^{1,3}$ Adeyemi O.S., \\ ${ }^{1,3}$ Ojo O.A., ${ }^{2,3}$ Evbuomwan I.O. and ${ }^{2,4}$ Olaniran A.F. \\ ${ }^{1}$ Department of Biochemistry, Landmark University P.M.B. 1001, Omu-Aran, Kwara State, Nigeria \\ ${ }^{2}$ Department of Food Science and Microbiology, Landmark University P.M.B. 1001, Omu-Aran, Kwara \\ State, Nigeria \\ ${ }^{3}$ Landmark University SDG 3 (Good Health and Wellbeing Research Group), Omu-Aran, Kwara State, \\ Nigeria \\ ${ }^{4}$ Landmark University SDG 12 (Responsible Consumption and Production Research Group), Omu-Aran, \\ Kwara State, Nigeria
}

\section{Article history:}

Received: 26 November 2020

Received in revised form: 13

January 2021

Accepted: 20 March 2021

Available Online: 13

February 2022

\section{Keywords:}

Walnut,

Cadmium chelation,

Metal toxicity,

Oxidative stress,

Dietary intervention,

Environmental toxicant

DOI:

https://doi.org/10.26656/fr.2017.6(1).683

\begin{abstract}
Tetracarpidium conophorum (African Walnut) is a plant with acclaimed multi-therapeutic properties in different parts of the plant. This research investigated the effect of fermented walnut supplemented diet on cadmium-induced toxicity in the liver and brain of rats. Twenty male Wistar rats were divided into four groups of five animals each weighing between 90-140 g. Group 1 received $5 \mathrm{mg} / \mathrm{kg}$ body weight cadmium chloride $\left(\mathrm{CdCl}_{2}\right)$ and normal rat feed. Group 2 received a normal rat diet while groups 3 and 4 received $5 \mathrm{mg} / \mathrm{kg}$ body weight of cadmium chloride, and $5 \%$ and $10 \%$ walnut supplemented feed respectively. Cadmium (Cd) was administered daily for 6 weeks by oral intubation. Rats were sacrificed $24 \mathrm{hrs}$ after the final treatment. Cd exposure elicited increased activities of Acetylcholinesterase, Superoxide dismutase, Catalase as well as elevated Glutathione levels. In addition, $\mathrm{Cd}$ exposure caused increases in rat plasma cholesterol and triglyceride concentration. The fermented walnut supplemented diet restored some rats' biochemical parameter to near normal comparable to control. Our study shows that walnut supplemented food could substantially moderate $\mathrm{Cd}$-induced toxicity in rat liver and brain while providing health and nutritional benefits. Hence, it could be useful for occupationally exposed individuals as a dietary intervention to reduce adverse health effects.
\end{abstract}

\section{Introduction}

Heavy metals among several environmental pollutants pose an insidious threat and have been gaining global attention in recent decades probably because of the phenomenal increase in population, economic development and anthropogenic activities in the industrial, agricultural and mining sectors (World Health Organization, 2019; Nasrollahi et al., 2020). Chemical pollutants released into different environmental matrices (water, soil and air) eventually reach the food chain from the environment and may eventually bio-accumulate in organisms.

Cadmium $(\mathrm{Cd})$ is one of the heavy metals that pose considerable environmental and occupational concerns. It is versatile and therefore applied for several industrial processes as a corrosion inhibitor, production of $\mathrm{Cd}$ batteries, as colour pigment and as neutron generator in nuclear power stations (Godt et al., 2006). Human exposure to $\mathrm{Cd}$, particularly among occupationally exposed employees, may present serious health challenges (Alli, 2019).

Previous studies reported that $\mathrm{Cd}$ triggers oxidative stress with quantitative abatement of antioxidant enzymes such as glutathione-S-transferase, superoxide dismutase and catalase in the central nervous system (Shagirtha et al., 2011). This supposed response of antioxidant enzymes is not sacrosanct as a few studies have reported a decline in the activities of these antioxidant enzymes in the brain on exposure to $\mathrm{Cd}$ (Shukla et al., 1996; Nemmiche et al., 2007; Zhang et al., 2009), suggesting that the fundamental basis for oxidative stress triggered by $\mathrm{Cd}$, cellular response and 
supposed functions is unpredictable. Cadmium causes an adverse effect on thiol status in the body. Cadmium has a high affinity for thiol in cysteine-rich metallothionein which is known to sequester heavy metals (Nishitai and Matsuoka, 2008), thus leading to oxidative stress.

Due to the adverse effect and cost of conventional orthodox pharmaceuticals in the treatment and management of diseases, there is a drive towards exploring the potential of natural product resource for nutritional and medicinal purposes. Consequently, investigations targeted at identifying natural food substances that can be used effectively to manage heavy metal toxicity with minimal side effects are welcome. A variety of plants such as garlic, ginger, onions, kola nut and green tea have been used to treat $\mathrm{Cd}$ and lead toxicity by way of dietary intervention (Zhai et al, 2015; Osemwegie et al., 2017).

The African walnut, Tetracarpidium conophorum has been reported as one of such plants. The walnut is a member of the Euphorbiaceae family. It is a climbing plant distributed in Southern Nigeria and the West African sub-region. It has a wrinkled two-lobed seed that is white in colour enclosed in a dark brown and hard shell. African walnut is a robust repository of protein, vitamins, polyphenol and antioxidants; and its oil is abundant in oleic acid, stearic acids, linolenic acid and mono-saturated fatty acids (Kanu et al., 2015). Many studies have ascertained the antioxidant (Amaeze et al., 2011), anticancer (Carvalho et al., 2010), chelating (Olabinri et al., 2010), antidiabetic (Odoemena et al., 2010), antiplasmodial (Dada and Ogundolie, 2016) and antilipidemic (Ezealisiji et al., 2016) properties of different parts of this tropical plant. Other documented benefits are the amelioration of reproductive toxicity (Akomolafe et al., 2015) and erectile dysfunction (Akomolafe et al., 2017). In light of the foregoing, rat animal model was used to evaluate the effect of fermented walnut-supplemented feed for protection against $\mathrm{Cd}$-induced toxicity.

\section{Materials and methods}

\subsection{Chemical and Reagent}

Chemicals and reagent used for this research were of analytical grade.

\subsection{Experimental animals}

A total of 20 male Wistar rats weighing between 90 $140 \mathrm{~g}$ were used for this study. The rats were acquired from the small Animal holding unit of the University of Ilorin. The animals were acclimatized for one week under room conditions with $12 \mathrm{hrs}$ light/dark cycle. The rats accessed normal rat feed and water ad libitum freely. The procedure for the handling of animal was approved by Landmark University Animal Care and Use Committee (LUAC - 0043B).

\subsection{Collection and preparation of plant material}

The African walnuts were purchased from the OkeOnigbin market, Kwara State and authenticated at the Herbarium Unit, Department of Plant Biology, University of Ilorin, Nigeria. The voucher number for the specimen is UILH/001/1102.

The shelled nuts were rinsed with clean water and removed from their pods. The de-shelled nuts were washed and cut into pieces. After three days of fermentation by submerging of pieced nut in distilled water $(1: 2 \mathrm{w} / \mathrm{v})$, it was filtered, oven-dried at $60^{\circ} \mathrm{C}$ and mechanically ground to obtain fine particles. The processed walnuts and rat feed were manually mixed together, in two varying concentrations to give 5\% and $10 \%$ walnut-supplemented feed respectively.

\subsection{Determination of proximate composition}

The standard guidelines as described by the Association of Official Analytical Chemists (AOAC, 2005) were followed for the determination of ash, crude fat and fibre, moisture content, carbohydrate and protein content of diets.

To determine the ash content, $20 \mathrm{~g}$ of each of the samples were placed in a furnace set at $550^{\circ} \mathrm{C}$ for $10 \mathrm{hrs}$ until ash was obtained. The ash content was calculated by using this formula: \% Ash $=(\mathrm{W} 3-\mathrm{W} 1) /(\mathrm{W} 2-\mathrm{W} 1) \mathrm{x}$ $100 \%$ where $\mathrm{W} 1$ = weight of oven-dried crucible, $\mathrm{W} 2=$ weight of crucible + sample before ashing, and W3 = weight of crucible + ash (AOAC, 2005).

Crude fat content was determined by employing the Soxhlet extraction technique (AOAC, 2005).

The crude fibre content was obtained by defatting 20 $\mathrm{g}$ of each sample with diethyl ether for $8 \mathrm{hrs}$ and boiled under reflux for exactly $30 \mathrm{~min}$ with $200 \mathrm{~mL}$ of $1.25 \%$ $\mathrm{H}_{2} \mathrm{SO}_{4}$. It was filtered and later washed with boiling water to remove the acid. The residue was then boiled in a round bottom flask with $200 \mathrm{~mL}$ of $1.25 \%$ sodium hydroxide for another 30 mins and filtered into a previously weighed crucible. The crucible was then dried with samples in an oven at $100^{\circ} \mathrm{C}$, left to cool in a desiccator and weighed. This was later incinerated in a muffle furnace at $600^{\circ} \mathrm{C}$ for 2 to $3 \mathrm{hrs}$ and later allowed to cool in a desiccator and weighed (AOAC, 2005).

The moisture content was determined based on moisture evaporation. The aluminium dishes were dried 
in the oven, cooled in desiccators and the weight of each dish was taken. A total of $5.0 \mathrm{~g}$ of samples were weighed into a sterile aluminium dish, weight of the dish and weight of the sample (in duplicate) were taken. This was transferred into an oven set at $80^{\circ} \mathrm{C}$ for $2 \mathrm{hrs}$ and $105^{\circ} \mathrm{C}$ for $3 \mathrm{hrs}$ respectively. This was removed and cooled in desiccators. Then the weight was measured using a measuring scale balance. It was transferred back into the oven for another one hour and then reweighed. The process continued until a constant weight was obtained. The difference in weight between the initial weight and the constant weight gained represents the moisture content (AOAC, 2005).

The carbohydrate value was calculated using this formula: Percentage of carbohydrates $(\%)=100 \%$ [moisture content $(\%)+$ Ash content + Crude fat content $(\%)+$ Crude protein content $(\%)+$ Ash content $(\%)]$.

The analysis of crude protein was carried out using the Kjeldahl method involving three steps (i.e. digestion, distillation and titration). The results of the protein content were expressed as percentage (\%) value (AOAC, 2005).

\subsection{Experimental protocol}

Twenty rats were shared without a definite plan into four groups, each subjected to definite treatment as follows for six weeks:

- Group one received $\mathrm{CdCl}_{2}$ (5 mg/kg body weight) and a normal diet without walnut,

- Group two received a normal diet only without walnut,

- Group three received $\mathrm{CdCl}_{2}(5 \mathrm{mg} / \mathrm{kg}$ body weight $)$ and 5\% walnut supplemented diet and

- Group four received $\mathrm{CdCl}_{2}$ (5 mg/kg body weight) and $10 \%$ walnut supplemented diet.

\subsection{Collection and preparation of experimental samples}

A whole day after exposure to the last dose and an overnight fast, the animals were sacrificed anaesthetically via light diethyl ether exposure. The liver and brain were excised and weighed. The blood samples were also collected into clean EDTA and heparin bottles for haematological and biochemical assays respectively. Sample of blood in heparin bottles was subsequently centrifuged for 10 mins at $5000 \times g$ to obtain plasma for further analysis.

The liver and brain were then homogenized in $0.1 \mathrm{M}$ phosphate buffer $(1: 4 \mathrm{w} / \mathrm{v})$ using a tissue homogenizer. The homogenates were centrifuged at $5000 \times g$ for 10 mins to obtain supernatant, which was collected with micropipette into sample bottles. The liver, brain homogenates and plasma were stored frozen at $-20^{\circ} \mathrm{C}$ until biochemical analyses were carried out.

\subsection{Biochemical analyses}

The biochemical indices were determined in the liver and brain homogenates, and plasma using UV/visible spectrophotometer (Jenway). The total protein, superoxide dismutase (SOD), reduced glutathione (GSH) and lipid peroxidation (MDA) were determined in both the liver and brain as described by Gornall et al. (1949) with slight modification, Misra and Fridovich (1972), Beutler et al. (1969) and Kei (1978) respectively. Liver Alkaline phosphatase (ALP) was determined as described by Wright et al. (1972). Also, brain acetylcholinesterase (AChE) was determined as described by Ellman et al. (1961). Randox assay kits (Crumlin, UK) were used to assess the lipid profile including cholesterol (TC) and triglyceride (TG) using the plasma.

\subsection{Haematological indices}

For the determination of white blood cells (WBC), red blood cells (RBC), haemoglobin (HGB), heamatocrit (HCT), mean corpuscular haemoglobin concentration (MCHC), mean cell volume (MCV), mean corpuscular haemoglobin (MCH) and platelet count (PLT), an automatic blood cell counter was used.

\subsection{Statistical analysis}

The results are expressed as mean \pm standard error of mean (SEM). Statistical differences in the mean values were determined using one-way analysis of variance (ANOVA) followed by Tukey post-hoc test on Graphpad Prism 5. Results with $\mathrm{p}<0.05$ were considered significant.

\section{Results}

The walnut supplemented diet was assessed for proximate composition using the AOAC methods. There was no significant difference in the content of crude lipid and crude fibre (Table 1). Ash content was significantly different from the control (normal diet) in both 5 and 10 $\%$ respectively. The walnut supplemented diet contained increasing protein content in the 5 and $10 \%$ respectively.

Cadmium exposure did not significantly change the rat's body, liver and brain weight as shown (Figure 1). Furthermore, while the liver-body weight ratio was not significantly altered, the brain-body weight ratio was significantly increased $(\mathrm{p}<0.05)$ in the group supplemented with $10 \%$ walnut.

Administration of walnut supplemented feed did not 
Table 1. Proximate composition (\%) of walnut supplemented feed

\begin{tabular}{lcccccc}
\hline & Crude fat & Moisture & Ash & Carbohydrate & Crude fibre & Crude protein \\
\hline $0 \%$ (CONTROL) & $8.38 \pm 0.85$ & $4.02 \pm 0.19$ & $2.92 \pm 0.03$ & $71.45 \pm 1.81$ & $2.79 \pm 0.43$ & $10.44 \pm 0.30$ \\
$5 \%$ & $7.64 \pm 0.56$ & $4.67 \pm 0.00$ & $13.27 \pm 0.75^{* *}$ & $59.26 \pm 0.41^{*}$ & $3.58+0.04$ & $11.59 \pm 0.18$ \\
$10 \%$ & $7.97 \pm 0.56$ & $1.39 \pm 0.31^{* *}$ & $10.87 \pm 0.52^{* *}$ & $64.7 \pm 0.90$ & $3.14 \pm 0.08$ & $11.92 \pm 0.23^{*}$ \\
\hline
\end{tabular}

Values are presented as mean $\pm \mathrm{SEM},(\mathrm{n}=2)$. Statistical difference is relative to control, ${ }^{*} \mathrm{P}<0.05$ and ${ }^{* *} \mathrm{P}<0.01$.
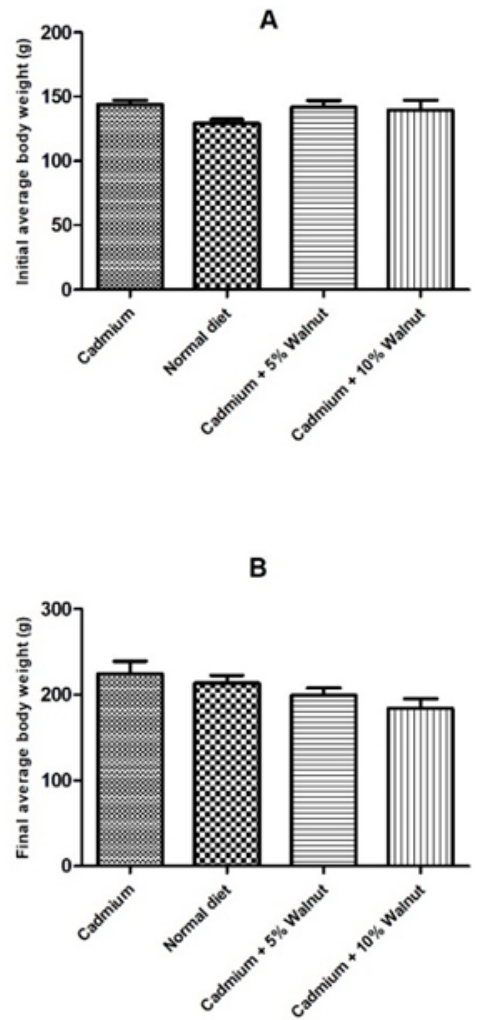

C

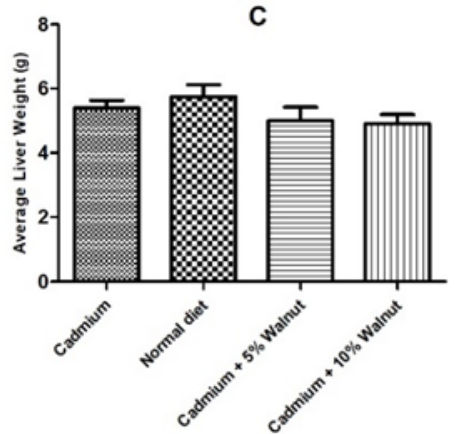

D

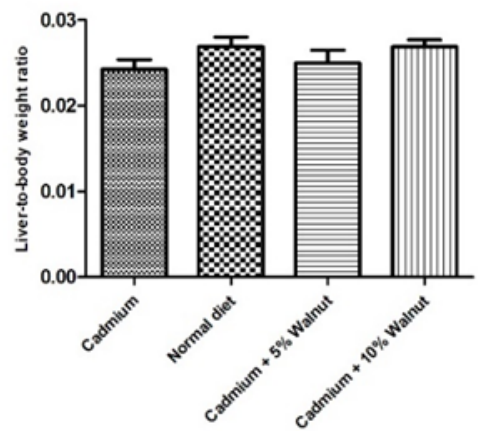

E

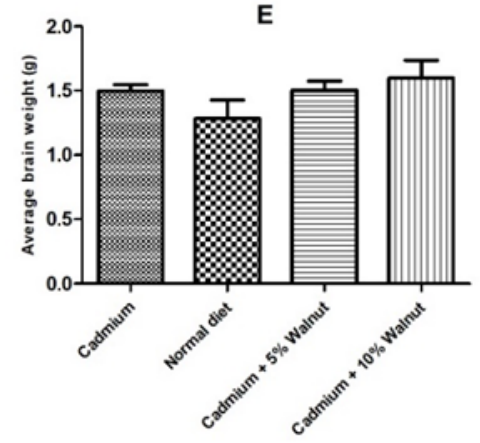

$\mathbf{F}$

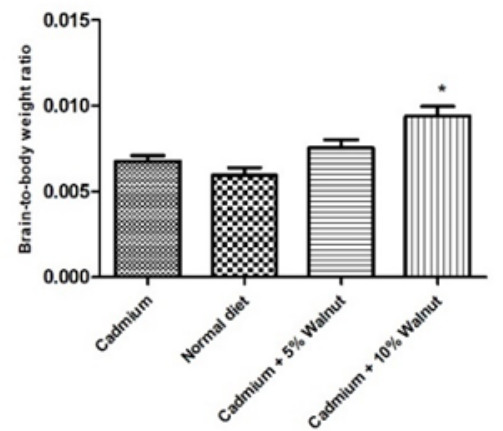

Figure 1. The effect of walnut supplemented diet. A: Initial rat weight; B: Final rat weight; C: Rat liver weight; D: Liver to body weight ratio; E: Rat brain weight; F: Liver to bodyweight ratio. Bars are mean $\pm \mathrm{SEM}, \mathrm{n}=5$. Statistical difference is relative to $\mathrm{Cd}, * \mathrm{P}<0.05$.
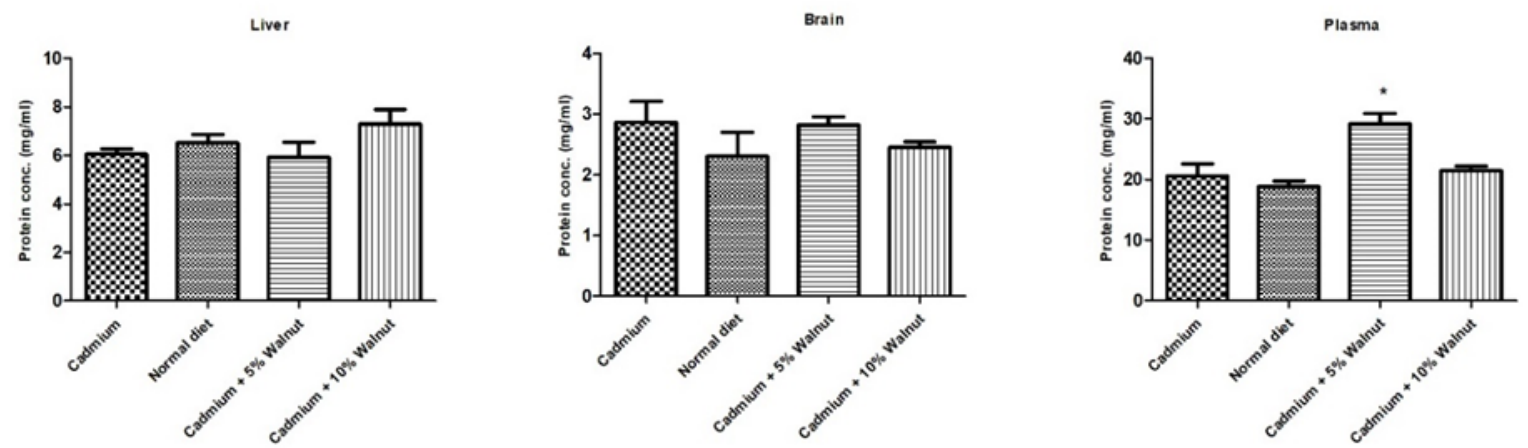

Figure 2. The effect of walnut supplemented diet on total protein concentration of rats administered with cadmium chloride. Bars are mean $\pm \mathrm{SEM}, \mathrm{n}=5$. Statistical difference is relative to $\mathrm{Cd}, * \mathrm{P}<0.05$.

significantly $(\mathrm{p}>0.05)$ alter the protein content of rat liver inconsistent responses. and brain when compared with the Cd group. However, a significant increase $(\mathrm{p} \leq 0.05)$ in rat plasma protein was observed in the group fed $5 \%$ walnut supplemented feed when compared Cd only group (Figure 2).

Exposure to $\mathrm{Cd}$ increased the acetylcholinesterase activity in the brain (Figure 3). Walnut supplementation reversed the trend relative to the control. The activity of alkaline phosphatase was suppressed due to $\mathrm{Cd}$ exposure while the two group of supplemented diet produced
The trend of the SOD and CAT were not consistent following supplementation with walnut to $\mathrm{Cd}$ intoxicated rats (Figure 4).

Exposure to Cd escalated SOD and CAT in both the liver and brain of rats. Supplementation with $5 \%$ and $10 \%$ walnut seemed to repress the antioxidant enzyme, especially in the liver.

Glutathione levels in the liver seem not to be 

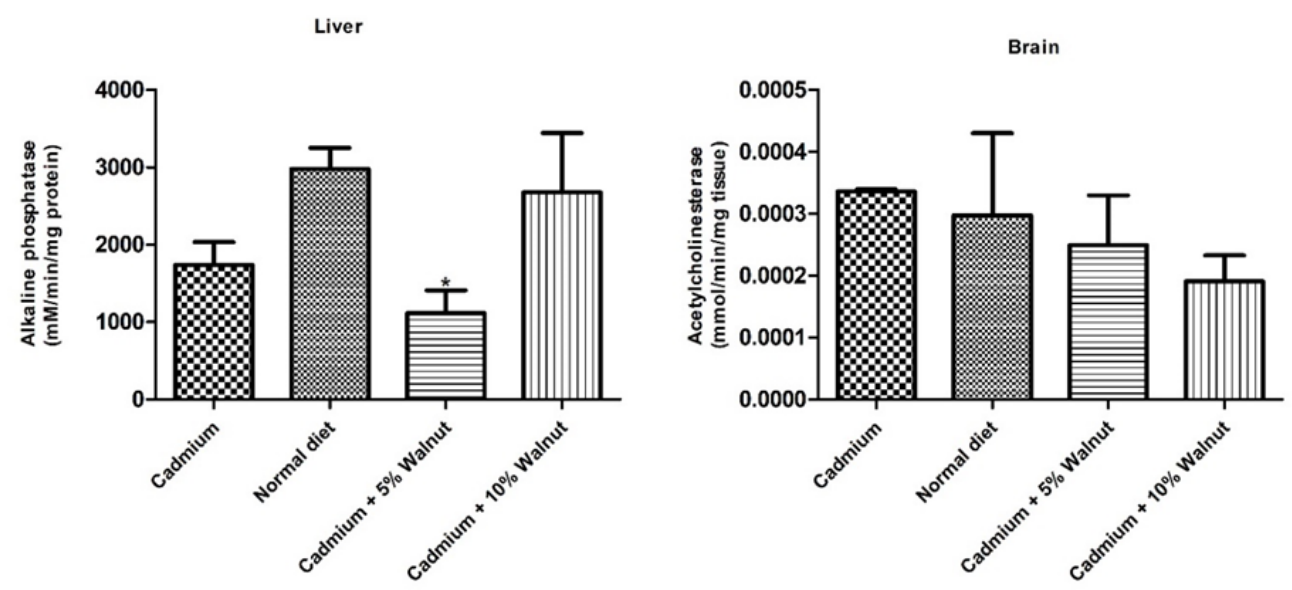

Figure 3. The effect of walnut supplemented diet on liver alkaline phosphatase and brain acetylcholinesterase activities of rats administered with cadmium chloride. Bars are mean $\pm \mathrm{SEM}, \mathrm{n}=5$. Statistical difference is relative to $\mathrm{Cd},{ }^{*} \mathrm{P}<0.05$.
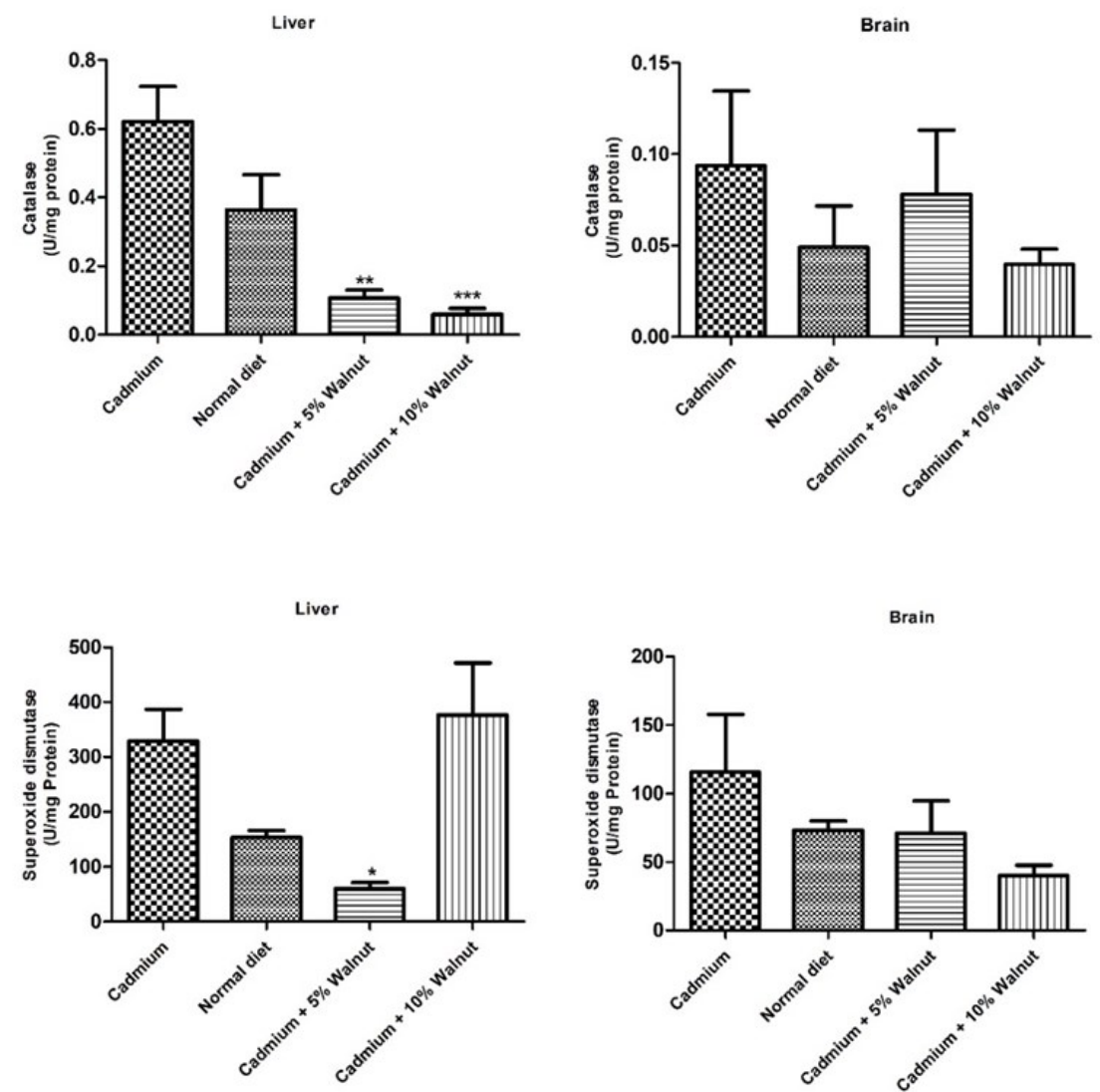

Figure 4. The effect of walnut supplemented diet on catalase and superoxide dismutase activity of rats administered with cadmium chloride. Bars are mean $\pm \mathrm{SEM}, \mathrm{n}=5$. Statistical difference is relative to $\mathrm{Cd}, * \mathrm{P}<0.05, * * \mathrm{P}<0.01$ and $* * * \mathrm{P}<0.001$.

Table 2. The effect of walnut supplemented feed on haematological parameters in rats administered with cadmium chloride

\begin{tabular}{ccccccccc}
\hline Group/Parameters & WBC & RBC & HGB & HCT & MCV & MCH & MCHC & PLT \\
\hline Cadmium & $9.70 \pm 5.95$ & $7.74 \pm 1.71$ & $11.63 \pm 2.45$ & $38.43 \pm 8.37$ & $49.70 \pm 0.82$ & $15.03 \pm 0.21$ & $30.27 \pm 0.81$ & $482.67 \pm 210.17$ \\
Normal diet & $7.83 \pm 8.03$ & $8.65 \pm 1.28$ & $13.10 \pm 2.77$ & $43.27 \pm 5.14$ & $50.13 \pm 1.33$ & $15.03 \pm 0.92$ & $30.03 \pm 2.66$ & $670.03 \pm 38.68$ \\
$5 \%$ Walnut Feed & $9.53 \pm 2.20$ & $8.64 \pm 0.34$ & $12.90 \pm 0.80^{\mathrm{a}}$ & $42.17 \pm 3.69$ & $48.77 \pm 2.34$ & $14.93 \pm 0.40$ & $30.63 \pm 1.07$ & $838.00 \pm 206.83$ \\
$10 \%$ Walnut Feed & $8.03 \pm 2.34$ & $8.27 \pm 0.96$ & $11.17 \pm 1.00$ & $39.40 \pm 5.05$ & $47.57 \pm 0.64$ & $13.67 \pm 2.31$ & $28.77 \pm 5.17$ & $549.67 \pm 79.46$ \\
\hline
\end{tabular}

Values are presented as mean \pm SEM, $n=5$.

significantly altered by supplementation with walnut across all the groups. However, the brain glutathione levels were significantly diminished following walnut supplementation in rats exposed to $\mathrm{Cd}$. Malondialdehyde concentration in the brain increased significantly on $\mathrm{Cd}$ exposure but this was tangibly normalized in both groups supplemented with walnut (Figure 5).

Exposure to $\mathrm{Cd}$ significantly $(\mathrm{P}<0.05)$ raised the cholesterol and triglyceride levels. Walnut supplemented diet upturned the Cd-induced perturbation in lipid profile (Figure 6). 

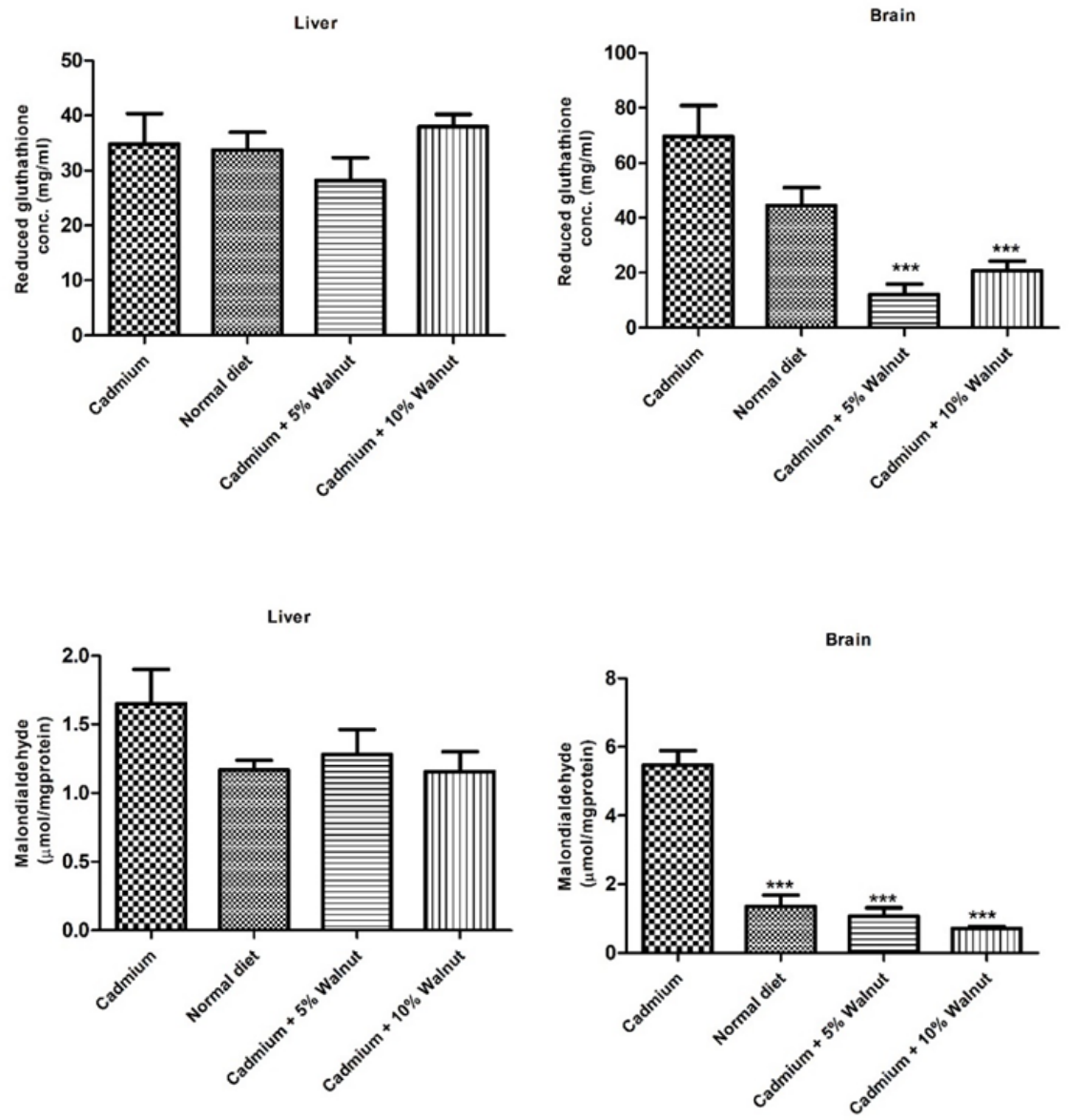

Figure 5. The effect of walnut supplemented diet on malondialdehyde and reduced glutathione level of rats administered cadmium chloride. Bars are mean $\pm \mathrm{SEM}, \mathrm{n}=5$. Statistical difference is relative to $\mathrm{Cd}, * * * \mathrm{P}<0.001$.
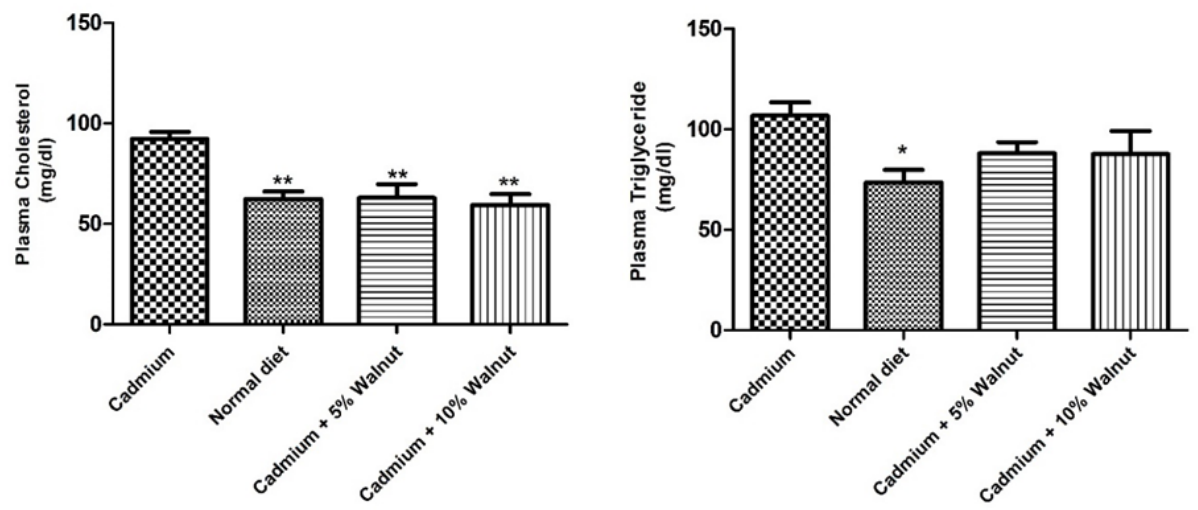

Figure 6. The effect of walnut supplemented diet on plasma cholesterol and triglyceride of rats administered with cadmium chloride only. Bars are mean $\pm \mathrm{SEM}, \mathrm{n}=5$. Statistical difference is relative to $\mathrm{Cd}, * \mathrm{P}<0.05$ and $* * \mathrm{P}<0.01$.

There was no significant difference observed in the haematological parameters across both supplemented groups compared to $\mathrm{Cd}$ only group. The group given $10 \%$ walnut was statistically similar to the control group in the concentration of platelets (Table 2).

\section{Discussion}

Cadmium is one of the most paramount environmental toxicants and serves no known biological function. Exposure to $\mathrm{Cd}$ through consumption of contaminated food and industrial occupation poses a considerable public health threat and has the propensity to cause dysfunction/impairment in several organs including the liver, kidney, brain, lungs, testes and ovaries (Claudio et al., 2019).

This current study explored the protective possibility of fermented walnut supplemented diet against $\mathrm{Cd}$ induced toxicity and oxidative stress in the liver and brain of male rats.

The proximate analysis of the supplemented diet showed slightly elevated levels of protein, ash and fibre content compared to the normal diet. This finding is in tandem with a previous study by Arinola and Adesin (2014) and may indicate the nutritional richness and health-enhancing benefits of walnut.

The current study revealed that levels of some blood parameters namely: RBC, haemoglobin, packed cell 
volume (HCT) and platelets were lowered in the $\mathrm{Cd}$ intoxicated rats. This result is in concert with previous investigations (Nikolić et al., 2015; Donmez et al., 2019). While a variety of tissues/organs are biochemically distressed on exposure to $\mathrm{Cd}$, Abadin et al. (2007) reported that the hematopoietic system and the blood represent a critical toxicity target of heavy metals such as $\mathrm{Pb}$ and $\mathrm{Cd}$. These metals can bind to the $\mathrm{RBC}$ membrane and plasma albumin and is then conveyed to the liver (Andjelkovic, 2019). However, this effect was clearly reversed in groups fed walnut supplemented-feed thereby protecting against $\mathrm{Cd}$ toxicity.

Prior investigations revealed that exposure to chemical toxicants may bring about an alteration in the weight of the body or organ which may indicate toxicity (Zhai et al., 2015; Nwonuma et al., 2016; Adeyemi et al., 2017). The exposure to $\mathrm{Cd}$ in this study brought about inconsistent alterations in the organ-to-body weight ratio in rat liver and brain. While the walnut supplemented diet in $\mathrm{Cd}$ exposed rats restored the weight of the liver compared to the group fed normal diet only, the supplemented feeds seem to have a hypertrophic effect on the brain which could possibly be indicative of neurotoxicity. This finding however is disagreeable with a report by Poulose et al. (2014) that polyphenolic compounds found in walnuts (Juglan regia) not only reduced the oxidant and inflammatory load on brain cells but also enhanced communication between neurons, increased the formation of neuron in the brain and facilitated sequestration of insoluble toxic protein aggregates.

In the present study, a non-significant increase in brain AChE activity was observed in the Cd exposed group relative to the control. Conclaves et al. (2012) similarly reported that dietary $\mathrm{Cd}$ exposure for five months raised AChE activity with concomitant impairment of cognitive function in rats. However, the walnut supplemented diet in this study seems to slightly reduce AChE activity. Some other researchers contrarily have reported a decrease in the AChE level in the brain following Cd intoxication (Abu-Taweel, 2016; Vijaya et al., 2020).

Liver alkaline phosphatase activity declined in the $\mathrm{Cd}$ exposed group but the two grades of walnut supplemented diet produced dose-independent outcomes. Treviño et al. (2015) reported that chronic exposure of $\mathrm{Cd}$ produces an in vivo inhibition of ALP with kinetic studies suggesting that inhibition of ALP occurs by a replacement of $\mathrm{Cd}$ by $\mathrm{Zn}$ in the native enzyme.

The antioxidant enzymes such as SOD and CAT which provide first-line defence against reactive oxygen species (ROS) were evaluated. Living organism normally produces ROS due to cellular metabolism. These perform vital physiological cell processes at low concentrations but at high concentrations, they could invoke cellular impairment to proteins, lipids and DNA (Birben et al., 2012).

SOD catalyses the dismutation of superoxide radicals to hydrogen peroxide $\left(\mathrm{H}_{2} \mathrm{O}_{2}\right)$ and subsequently degraded to generate one molecule of each of water $\left(\mathrm{H}_{2} \mathrm{O}\right)$ and oxygen $\left(\mathrm{O}_{2}\right)$ by catalase (Gravato et al., 2006). While the liver SOD activity increased significantly in the group administered $\mathrm{Cd}$, there was a decrease in its activity in the brain relative to the control. Walnut supplementation remarkably enhanced the liver SOD activity of $\mathrm{Cd}$ exposed rat probably due to the rich polyphenols which have the potential to modulate oxidative stress. However, the brain SOD was significantly depressed by $\mathrm{Cd}$, but these effects seem unamended by the supplementation.

MDA is a major biomarker of oxidative stress and the most often studied product of lipid peroxidation. Cellular membrane lipids and proteins could become oxidatively impaired in the highly oxidized environment created as a result of elevated levels of free radicals and ROS (Khan et al., 2015).

In this study, $\mathrm{Cd}$ exposure triggered an increase in MDA level and reduced glutathione in rat's liver and much more in the brain relative to the rats fed a normal diet. The high level of MDA in both the liver and brain of $\mathrm{Cd}$ exposed rats indicate possible oxidation in the lipid and protein which form the membrane components leading to the generation of ROS in these vital organs.

In a related study, Ogunrinola et al. (2015) reported a dose-dependent $(100,200$ and $300 \mathrm{ppm} \mathrm{Cd})$ increase of MDA level in the liver and brain of rat exposed to $\mathrm{Cd}$ relative to control. Meanwhile, MDA level was drastically abated in the walnut supplemented group exposed to Cd similarly to a normal diet, attesting to the radical scavenging potential of walnut.

Several epidemiological studies have reported that elevated concentration of plasma cholesterol due to dietary or occupational exposure to a toxicant is an important risk factor for cardiovascular disease (Ademuyiwa et al., 2005). Cadmium has been reported to adversely affect lipid profile by way of inducing lipid peroxidation (Olisekodiaka et al., 2012). Furthermore, exposure to $\mathrm{Cd}$ perturbed the lipid profile substantially increasing cholesterol and triglyceride levels in the rat exposed to Cd only, but again the inclusion of walnut in the rat diet reversed these alterations of lipid profile. These outcomes agree with previous findings which have established the perturbation of lipid profile by $\mathrm{Cd}$ 
exposure in rats (Samarghandian et al., 2015) and the lipid-lowering and cardioprotective effect of walnut (Banel and $\mathrm{Hu}, 2009$; Bashan and Bakman, 2018). The modulatory effect of walnut diet improved blood parameters, ameliorated oxidative stress and restored lipid profile alteration necessitating its incorporation in the routine diet for improved wellness and health.

\section{Conclusion}

Conclusively, the walnut supplementation in this study appears to have abated the heavy metal toxicity due to the abundant ions/phytochemicals present in the nut. These results suggest that heavy metal intoxication could be managed variably by the nutritional benefits of walnut supplement in food.

\section{Conflict of interest}

The authors declare no conflict of interest.

\section{Acknowledgements}

The authors would like to appreciate the laboratory technologists in the Department of Biochemistry, Landmark University, Omu-Aran Kwara State, Nigeria. Furthermore, Landmark University Centre for Research, Innovation and Discovery, Omu-Aran, Kwara State is gratefully acknowledged for the payment of the article publication charges.

\section{References}

Abadin, H., Ashizawa, A., Stevens, Y.-W., Llados, F., Diamond, G., Sage, G., Citra, M., Quinones, A., Bosch, S.J. and Swarts, S.G. (2007). A framework to guide public health assessment decisions at lead sites. Toxicological Profile for Lead. USA: Agency for Toxic Substances and Disease Registry (US).

Abu-Taweel, G.M. (2016). Effects of curcumin on the social behavior, blood composition, reproductive hormones in plasma and brain acetylcholinesterase in cadmium intoxicated mice. Saudi Journal of Biological Sciences, 23(2), 219-228. https:// doi.org/10.1016/j.sjbs.2015.05.010

Ademuyiwa, O., Ugbaja, R.N., Idumebor, F. and Adebawo, O. (2005). Plasma lipid profiles and risk of cardiovascular disease in occupational lead exposure in Abeokuta, Nigeria. Lipids in Health and Disease, 4(1), 19. https://doi.org/10.1186/1476-511X $-4-19$

Adeyemi, O.S., Aroge, C.S. and Akanji, M.A. (2017). Moringa oleifera-based diet protects against nickelinduced hepatotoxicity in rats. Journal of Biomedical Research, 31(4), 350-357.
Akomolafe, S., Oboh, G., Olasehinde, T., Oyeleye, S. and Ogunsuyi, O. (2017). Modulatory effects of Aqueous extract from Tetracarpidium conophorum leaves on key enzymes linked to erectile dysfunction and oxidative stress-induced lipid peroxidation in penile and testicular tissues. Journal of Applied Pharmaceutical Science, 7(1), 51-56. https:// doi.org/10.7324/JAPS.2017.70107

Akomolafe, S.F., Oboh, G., Akindahunsi, A.A. and Afolayan, A.J. (2015). Tetracarpidium conophorum (Mull. Arg) Hutch and Dalziel inhibits $\mathrm{FeSO}_{4-}$ induced lipid peroxidation in rat's genitals. $B M C$ Complementary and Alternative Medicine, 15, 57. https://doi.org/10.1186/s12906-015-0547-1

Alli, L.A. (2015). Blood level of cadmium and lead in occupationally exposed persons in Gwagwalada, Abuja, Nigeria. Interdisciplinary Toxicology, 8(3), 146-150. https://doi.org/10.1515/intox-2015-0022

Amaeze, O.U., Ayoola, G.A., Sofidiya, M.O., AdepojuBello, A.A., Adegoke, A.O. and Coker, H.A.B. (2011). Evaluation of antioxidant activity of Tetracarpidium conophorum (Müll. Arg) Hutch and Dalziel leaves. Oxidative Medicine and Cellular Longevity, 2011, $976701 . \quad \mathrm{https} / /$ doi.org/10.1155/2011/976701.

Andjelkovic, M., Buha Djordjevic, A., Antonijevic, E., Antonijevic, B., Stanic, M., Kotur-Stevuljevic, J., Spasojevic-Kalimanovska, V., Jovanovic, M., Boricic, N., Wallace, D. and Bulat, Z. (2019). Toxic effect of acute cadmium and lead exposure in rat blood, liver, and kidney. International Journal of Environmental Research and Public Health, 16(2), 274. https://doi.org/10.3390/ijerph16020274

Arinola, S.O. and Adesina, K. (2014). Effect of thermal processing on the nutritional, antinutritional, and antioxidant properties of Tetracarpidium conophorum (African Walnut). Journal of Food Processing, 2014, $418380 . \quad \mathrm{https}: / /$ doi.org/10.1155/2014/418380

AOAC. (2005). Official Methods of Analysis. Association of Official Analytical Chemists. $18^{\text {th }}$ ed. Arlington, VA, USA: AOAC.

Banel, D.K. and Hu, F.B. (2009). Effects of walnut consumption on blood lipids and other cardiovascular risk factors: a meta-analysis and systematic review. The American Journal of Clinical Nutrition, 90(1), 56-63. https://doi.org/10.3945/ ajcn.2009.27457

Bashan, I. and Bakman, M. (2018). The Effect of Daily Walnut Consumption on Dyslipidemia. Journal of Food Quality, 2018, 4731826. https:// doi.org/10.1155/2018/4731826 
Beutler, E. (1969). Drug-induced hemolytic anemia. Pharmacological Reviews, 21(1), 73-103.

Birben, E., Sahiner, U.M., Sackesen, C., Erzurum, S. and Kalayci, O. (2012). Oxidative stress and antioxidant defense. World Allergy Organization Journal, 5(1), 9 $-19$.

\section{WOX.0b013e3182439613}

Carvalho, M., Ferreira, P.J., Mendes, V.S., Silva, R., Pereira, J.A., Jerónimo, C. and Silva, B.M. (2010). Human cancer cell antiproliferative and antioxidant activities of Juglans regia L. Food and Chemical Toxicology, 48(1), 441-447. https://doi.org/10.1016/ j.fct.2009.10.043

Claudio, S.R., Ribeiro, F.A.P., De Lima, E.C., Santamarina, A.B., Pisani, L.P., Pereira, C.S.D., Oshima, C.T.F. and Ribeiro, D.A. (2019). The protective effect of grape skin or purple carrot extracts against cadmium intoxication in kidney of rats. Pathophysiology, 26(3-4), 263-269. https:// doi.org/10.1016/j.pathophys.2019.07.001

Dada, E.O. and Ogundolie, O.O. (2016). In vivo antiplasmodial activity of raw ethanolic seed extract of Tetracarpidium conophorum in Swiss albino mice infected with Plasmodium berghei. Journal of Advances in Medical and Pharmaceutical Sciences, 9(2), 1-8. $\quad$ https://doi.org/10.9734/ JAMPS/2016/26789

Donmez, H.H., Donmez, N., Kisadere, I. and Undag, I. (2019). Protective effect of quercetin on some hematological parameters in rats exposed to cadmium. Biotechnic and Histochemistry, 94(5), 381 -386 . https:// doi.org/10.1080/10520295.2019.1574027

Ellman, G.L., Courtney, K.D., Andres Jr, V. and Featherstone, R.M. (1961). A new and rapid colorimetric determination of acetylcholinesterase activity. Biochemical Pharmacology, 7(2), 88-95. https://doi.org/10.1016/0006-2952(61)90145-9

Ezealisiji, K.M., Stanley, C.N. and Ekanem, E.S. (2016). Evaluation of anti-cholesterol activity of ethyl acetate and n-hexane extracts of Tetracarpidium conophorum (Mull. Arg.) Hutch and Dalziel (African walnut) towards hypercholesterolemic rats. International Journal of Pharmacognosy and Phytochemical Research, 8(8), 1372-1376.

Godt, J., Scheidig, F., Grosse-Siestrup, C., Esche, V., Brandenburg, P., Reich, A. and Groneberg, D.A. (2006). The toxicity of cadmium and resulting hazards for human health. Journal of Occupational Medicine and Toxicology, 1(1), 1-6. https:// doi.org/10.1186/1745-6673-1-22

Gornall, A.G., Bardawill, C.J. and David, M.M. (1949).
Determination of serum proteins by means of the biuret reaction. Journal of Biological Chemistry, 177 (2), 751-766. https://doi.org/10.1016/S0021-9258 (18)57021-6

Gravato, C., Teles, M., Oliveira, M. and Santos, M.A. (2006). Oxidative stress, liver biotransformation and genotoxic effects induced by copper in Anguilla anguilla L.-the influence of pre-exposure to $\beta$ naphthoflavone. Chemosphere, 65(10), 1821-1830. https://doi.org/10.1016/j.chemosphere.2006.04.005

Kanu, A.M., Kalu, J.E. and Okorie, A.C. (2015). Nutritional and health values of African walnut (Tetracarpidium conophorum). International Journal of Scientific and Technology Research, 4(9), 215-220.

Kei, S. (1978). Serum lipid peroxide in cerebrovascular disorders determined by a new colorimetric method. Clinica Chimica Acta, 90(1), 37 -43. https:// doi.org/10.1016/0009-8981(78)90081-5

Khan, M.H.A. and Parvez, S. (2015). Hesperidin ameliorates heavy metal induced toxicity mediated by oxidative stress in brain of Wistar rats. Journal of Trace Elements in Medicine and Biology, 31, 53-60. https://doi.org/10.1016/j.jtemb.2015.03.002

Misra, H.P. and Fridovich, I. (1972). The role of superoxide anion in the autoxidation of epinephrine and a simple assay for superoxide dismutase. Journal of Biological Chemistry, 247(10), 3170-3175. https://doi.org/10.1016/S0021-9258(19) 45228-9

Nasrollahi, Z., Hashemi, M.S., Bameri, S. and Taghvaee, V.M. (2020). Environmental pollution, economic growth, population, industrialization, and technology in weak and strong sustainability: using STIRPAT model. Environment, Development and Sustainability, 22(2), 1105-1122. https:// doi.org/10.1007/s10668-018-0237-5

Nemmiche, S., Chabane-Sari, D. and Guiraud, P. (2007). Role of $\alpha$-tocopherol in cadmium-induced oxidative stress in Wistar rat's blood, liver and brain. ChemicoBiological Interactions, 170(3), 221-230. https:// doi.org/10.1016/j.cbi.2007.08.004

Nikolić, R., Krstić, N., Jovanović, J., Kocić, G., Cvetković, T.P. and Radosavljević-Stevanović, N. (2015). Monitoring the toxic effects of $\mathrm{Pb}, \mathrm{Cd}$ and $\mathrm{Cu}$ on hematological parameters of Wistar rats and potential protective role of lipoic acid and glutathione. Toxicology and Industrial Health, 31(3), 239-246.

https:// doi.org/10.1177/0748233712469652

Nishitai, G. and Matsuoka, M. (2008). Differential regulation of HSP70 expression by the JNK kinases 
SEK1 and MKK7 in mouse embryonic stem cells treated with cadmium. Journal of Cellular Biochemistry, 104(5), 1771-1780. https:// doi.org/10.1002/jcb.21743

Nwonuma, C.O., Irokanulo, E.O., Iji, C.E., Alejolowo, O.O. and Adetunji, C.O. (2016). Effect of Thaumatococcus daniellii leaf rat-feed on potassium bromate induced testicular toxicity. Asian Pacific Journal of Reproduction, 5(6), 500-505. https:// doi.org/10.1016/j.apjr.2016.10.014

Odoemena, C.I., Udosen, I.R. and Sam, S.M. (2010). Anti-diabetic Activity of Tetracarpidium conophorum Muell Arg. (Hutchz and Dalz) Ethanolic Seed Extract on Diabetic Rats. Advances in Science and Technology, 4(2), 120-124.

Ogunrinola, O.O. (2015). Lipid profile and malondialdehyde concentrations in cadmiuminduced rats: a study with relation to doses. MOJ Toxicology, 1(5), 1-6. https://doi.org/10.15406/ mojt.2015.01.00022

Olabinri, B.M., Eniyansoro, O.O., Okoronkwo, C.O., Olabinri, P.F. and Olaleye, M.T. (2010). Evaluation of chelating ability of aqueous extract of Tetracarpidium conophorum (African walnut) in vitro. International Journal of Applied Research in Natural Products, 3(3), 13-18.

Olisekodiaka, M.J., Igbeneghu, C.A., Onuegbu, A.J., Oduru, R. and Lawal, A.O. (2012). Lipid, lipoproteins, total antioxidant status and organ changes in rats administered high doses of cadmium chloride. Medical Principles and Practice, 21(2), 156-159. https://doi.org/10.1159/000333385

Osemwegie, O.O., Nwonuma, C.O., Oluyori, A.P., Abraham, P.O., Akanbi, A.A., Opaleke, D.O. and Alejolowo, O.O. (2017). In vitro antimicrobial and in vivo lead acetate poison abatement study of Garcinia kola Heckel. Journal of Taibah University for Science, 11(6), 883-894. https://doi.org/10.1016/ j.jtusci.2017.06.001

Poulose, S.M., Miller, M.G. and Shukitt-Hale, B. (2014). Role of walnuts in maintaining brain health with age. The Journal of Nutrition, 144(4), 561S-566S. https://doi.org/10.3945/jn.113.184838

Samarghandian, S., Azimi-Nezhad, M., Shabestari, M.M., Azad, F.J., Farkhondeh, T. and Bafandeh, F. (2015). Effect of chronic exposure to cadmium on serum lipid, lipoprotein and oxidative stress indices in male rats. Interdisciplinary Toxicology, 8(3), 151154. https://doi.org/10.1515/intox-2015-0023

Shagirtha, K., Muthumani, M. and Prabu, S.M. (2011). Melatonin abrogates cadmium induced oxidative stress related neurotoxicity in rats. European Review for Medical and Pharmacological Sciences, 15(9),
1039-1050.

Shukla, A., Shukla, G.S. and Srimal, R.C. (1996). Cadmium-induced alterations in blood-brain barrier permeability and its possible correlation with decreased microvessel antioxidant potential in rat. Human and Experimental Toxicology, 15(5), 400 -405. https://doi.org/10.1177/096032719601500507

Treviño, S., Andrade-García, A., Herrera Camacho, I., León-Chavez, B.A., Aguilar-Alonso, P., Flores, G., and Brambila, E. (2015). Chronic cadmium exposure lead to inhibition of serum and hepatic alkaline phosphatase activity in wistar rats. Journal of Biochemical and Molecular Toxicology, 29(12), 587594. https://doi.org/10.1002/jbt.21732

Vijaya, P., Kaur, H., Garg, N. and Sharma, S. (2020). Protective and therapeutic effects of garlic and tomato on cadmium-induced neuropathology in mice. The Journal of Basic and Applied Zoology, 81 (1), 1-11. https://doi.org/10.1186/s41936-020-001604

World Health Organization. (2019). Preventing disease through healthy environments: exposure to highly hazardous pesticides: a major public health concern (No. WHO/CED/PHE/EPE/19.4. 6). Geneva: World Health Organization.

Wright, P.J., Leathwood, P.D. and Plummer, D.T. (1972). Enzymes in rat urine: alkaline phosphatase. Enzymologia, 42(4), 317-327.

Zhai, Q., Narbad, A. and Chen, W. (2015). Dietary strategies for the treatment of cadmium and lead toxicity. Nutrients, 7(1), 552-571. https:// doi.org/10.3390/nu7010552

Zhang, Y.M., Xue-Zhong, L.I.U., Hao, L.U., Li, M.E.I. and Zong-Ping, L.I.U. (2009). Lipid peroxidation and ultrastructural modifications in brain after perinatal exposure to lead and/or cadmium in rat pups. Biomedical and Environmental Sciences, 22 (5), 423-429. https://doi.org/10.1016/S0895-3988 (10)60021-9 